\title{
Bone Anchoring for the Correction of Posterior Nasal Septum
}

\author{
Sung Jae Heo, Eun Joo Cha, Ji Hye Park, Hak Geon Kim, and Jung Soo Kim \\ Department of Otorhinolaryngology-Head and Neck Surgery, School of Medicine, Kyungpook National University, Daegu, Korea
}

\author{
골고정법을 이용한 후방 비중격 교정 \\ 허성재 - 차은주 - 박지혜 - 김학건 - 김정수 \\ 경북대학교 의과대학 이비인후-두경부외과학교실
}

\author{
Received August 7, 2017 \\ Revised September 23, 2017 \\ Accepted October 13, 2017 \\ Address for correspondence \\ Jung Soo Kim, MD \\ Department of Otorhinolaryngology- \\ Head and Neck Surgery, \\ School of Medicine, \\ Kyungpook National University, \\ 130 Dongdeok-ro, Jung-gu, \\ Daegu 41944, Korea \\ Tel $+82-53-420-5777$ \\ Fax $+82-53-423-4524$ \\ E-mail profsookim@gmail.com
}

Background and Objectives Various techniques have been reported for the correction of deviated nasal septum, most of them for caudal septal cartilage. For deviated posterior septal cartilage, the typical method of the day is the resection of deviated portion. However, we developed a bone anchoring technique that conservatively corrects deviated posterior septal cartilage. The aim of the current study is to determine the efficacy of this bone anchoring technique. Subjects and Method The patients who had undergone septoplasty using bone anchoring technique by a single surgeon (J.S.K) between October 2015 and June 2016 were enrolled in this study. The result of the surgery was evaluated using a visual analogue scale (VAS, ranged 0 - 10) for nasal obstruction, acoustic rhinometry, and assessment of surgeon.

Results A total of 44 patients were included in this study. The VAS of nasal obstruction was significantly decreased after surgery from $7.5 \pm 1.7$ to $2.4 \pm 1$.4. In acoustic rhinometry, minimal cross-sectional area and volume were increased after surgery from $0.35 \pm 0.18$ to $0.52 \pm$ $1.40 \mathrm{~cm}^{2}$ and from $3.6 \pm 1.1$ to $5.8 \pm 1.5 \mathrm{~cm}^{3}$, respectively. Most of the deviated septum was well corrected, and complication or recurrence did not developed.

Conclusion Bone anchoring technique is easy to perform. It enables the preservation of septal cartilage, which is useful in revision septoplasty or rhinoplasty. We conclude that this technique is a good method for the correction of deviated posterior septal cartilage. Korean J Otorhinolaryngol-Head Neck Surg 2018;61(3):139-42

Key Words Cartilage - Nasal septum - Reconstructive surgical procedures - Surgery.

\section{서 론}

비중격 만곡은 코막힘을 유발하는 흔한 원인 중 하나로 그 형태와 정도는 사람마다 다르다. 비중격 교정술은 비중격 만곡을 교정하는 수술법으로, 좁은 비강으로 수술 도구를 삽입해서 조작해야 하며 개개인에 따라 다양한 형태를 가지 는 비중격 만곡의 특성으로 인해 비교적 난이도가 높은 수술

This is an Open Access article distributed under the terms of the Creative Commons Attribution Non-Commercial License (http://creativecommons.org/licenses/by-nc/4.0) which permits unrestricted non-commercial use, distribution, and reproduction in any medium, provided the original work is properly cited.
이다. 지금까지 소개된 수술법에는 비강내 접근법으로 점막하 절제술(submucous resection)이나 교차절개법(crosshatching incision)과 같이 비교적 침습적인 방법들과 봉합 술식들(suture techniques)이나 부목 이식(batten graft)과 같은 보존적 인 방법들, 비강외 접근법인 체외교정술 등 다양한 방법들이 있다. $^{1-4)}$

저자들은 환자에 따라서 부목 이식이나 체외교정술 등의 방 법도 사용하지만, 주로 고정봉합(anchoring suture)을 사용하 고 있고 좋은 결과를 보여 왔다. ${ }^{5)}$ 고정봉합법은 비중격과 전비 극(anterior nasal spine) 주위의 연부 조직을 봉합하여 비중격 
연골을 중앙(midline)에 고정하는 방법이다. 이 방법의 단점은 실이 비중격의 앞 부위에서 주로 통과하여 만곡된 비중격의 앞부분을 당기기 때문에, 비중격 연골 중간 부위와 후방의 만곡 교정에는 한계가 있다. 따라서 저자들은 비중격 연골 후 반부의 만곡이 있는 경우 비중격 연골을 사골 수직판에 고정 하는 골고정법(bone anchoring)을 고안해서 시행하여 좋은 결과를 보여 이를 보고하는 바이다.

\section{대상 및 방법}

2015년 10월부터 2016년 6월까지 본원 이비인후과에서 단 일 술자(J.S.K)에게 비중격 교정술을 받은 환자 중 골고정법을 사용한 환자를 대상으로 하였고, 재수술이거나 부비동 내시경 수술이나 비성형술을 함께 시행한 경우, 추적관찰 기간이 1년 미만인 경우, 기록이 불충분한 경우는 제외하였다. 연구는 본 대학병원 임상연구심의위원회의 승인(IRB No. KNUH201707-028)을 받은 후 후향적으로 진행되었다.

수술 전 비중격 만곡을 주된 만곡 부위, 만곡의 정도, Guyuron 분류법()으로 평가하였다. 주된 만곡 부위는 배부, 미부, 중간 또는 후방 부위, 능선(crest)으로 나누었고, 만곡의 정도 는 비중격 만곡이 비중격과 측벽과의 거리의 반 이하일 때 경 도, 반 이상일 때 중등도, 비중격이 측벽에 닿았을 때 심도로 분류하였다.

본 연구에 포함된 환자의 비중격 교정술 방법은 오목면의 비중격 미부에 15 번 칼(blade)을 사용하여 반관통절개(hemitransfixion incision)를 시행 후 Freer 거상기로 연골막을 들 어올렸다. 일측 또는 양측의 연골막과 골막을 충분히 거상한 후 비중격 연골을 사골 수직판 및 서골과 분리하였다. 비중격 골의 교정은 약목 골절(greenstick fracture)로 고정하였는데, 골절시킬 때 뇌척수액 누출이나 keystone 부위 손상 등의 합 병증을 예방하고 골절을 용이하게 하기 위해 골절시킬 부위

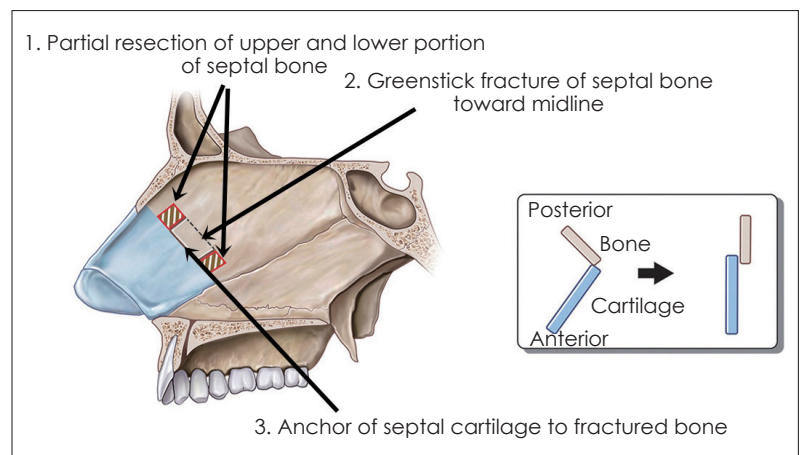

Fig. 1. Schematic drawing of bone anchoring technique. Perpendicular plate of ethmoid bone is cut at the superior position and fractured toward midline of nasal septum. Posterior portion of septal cartilage is anchored to fractured perpendicular plate.
의 윗부분과 아랫부분의 골을 먼저 골가위나 비갑개 절제가 위로 자르거나 일부 절제한 후 만곡된 골을 중간 위치로 골 절시켰다(Figs. 1 and 2). 비중격 연골의 후방 교정은 만곡된 연골이 중간에 위치하면 잉여 부위가 발생하는데 그 잉여 연 골을 골절로 중간에 위치시킨 골에 겹치게(overlap) 하여 교 정하였다. 만곡된 비중격의 뒷부분은 이와 같은 골고정법을 이용하여 교정하고, 비중격 연골 앞부분은 잉여 연골의 아래 쪽 수 $\mathrm{mm}$ 를 제거하여 연골이 이동할 수 있는 공간을 확보한 후 필요 시 전비극와 연골을 분리시켜 비중격에 작용하는 장 력을 최소화하였다. 비중격 연골이 만곡을 만드는 힘으로부 터 자유로워지면 전비극 주위의 연부 조직과 비중격을 봉합 하는 고정봉합법을 이용하여 교정하였다. 교정 후 절개 부위 를 봉합하고 관통봉합(quilting mattress suture)을 시행하였 다. 비중격 교정술 후에는 coblator(Coblator II controller; Arthrocare, Sunnyvale, CA, USA)를 이용한 하비갑개 수술 을 시행하였고, 패킹을 한 후 수술을 종료하였다.

수술결과는 수술 전과 수술 6개월 후에 시행한 코막힘 visual analogue scale(VAS), 음향 비강통기도 검사, 술자가 판 단한 비중격 교정 정도로 평가하였다. VAS 점수는 코막힘이 없는 경우를 0 점, 코막힘이 매우 심한 경우를 10 점으로 하였 고, 음향 비강통기도 검사는 비점막 수축 후 만곡이 있는 비 강 입구 $2 \mathrm{~cm}$ 에서 $5.4 \mathrm{~cm}$ 사이의 최소 단면적과 부피로 평 가하였다. 술자의 평가는 아주 잘 교정됨, 잘 교정됨, 양호함, 교정이 잘 안 됨, 수술 전보다 악화됨 등 총 5 등급으로 나누 어서 평가하였다. 통계는 SPSS statistics version 18.0(SPSS Inc., Chicago, IL, USA)을 이용하여 paired t-test를 시행하여 결과값을 비교하였고, $p$ value가 0.05 미만인 경우에 통계적 으로 유의한 것으로 판단하였다.

\section{결 과}

총 44명의 환자가 본 연구에 포함되었고, 남자가 39명, 여

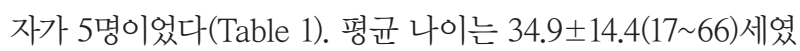
고, 평균 추적관찰 기간은 $14.0 \pm 1.7(12$ 20)개월이었으며, 모 든 수술은 국소마취로 시행되었다. 44명 중 13명이 외상 병력 이 있었고, 5 명에서 수술 중 비중격 골절이 관찰되었다. 수술 전 비중격 만곡은 좌측으로 만곡이 26명으로 우측 방향보다 많았고, 주된 만곡 부위는 미부가 18명으로 가장 많았고, 다 음으로는 중간 또는 후방 13 명, 배부 7명, 능선 6명이었다. 만 곡의 정도는 심도 8 명, 중등도 32 명, 경도 4명이었고, Guyuron 분류에서 II가 21명으로 가장 많았고, III가 10 명, IV가 8명, $\mathrm{V}$ 가 5명이었다. 수술 시 일측 피판 거상은 11 명, 양측 거상은 33 명에서 시행되었고, 1 명의 환자에서는 부목 이식(batten graft) 
Fig. 2. Bone anchoring technique. Preoperative endoscopic view of deviated nasal septum (A). Perpendicular plate of ethmoid bone is cut at superior portion and fractured into midline (B). Posterior septal cartilage is anchored into fractured perpendicular plate of ethmoid bone (C). Postoperative endoscopic view of corrected nasal septum (D).
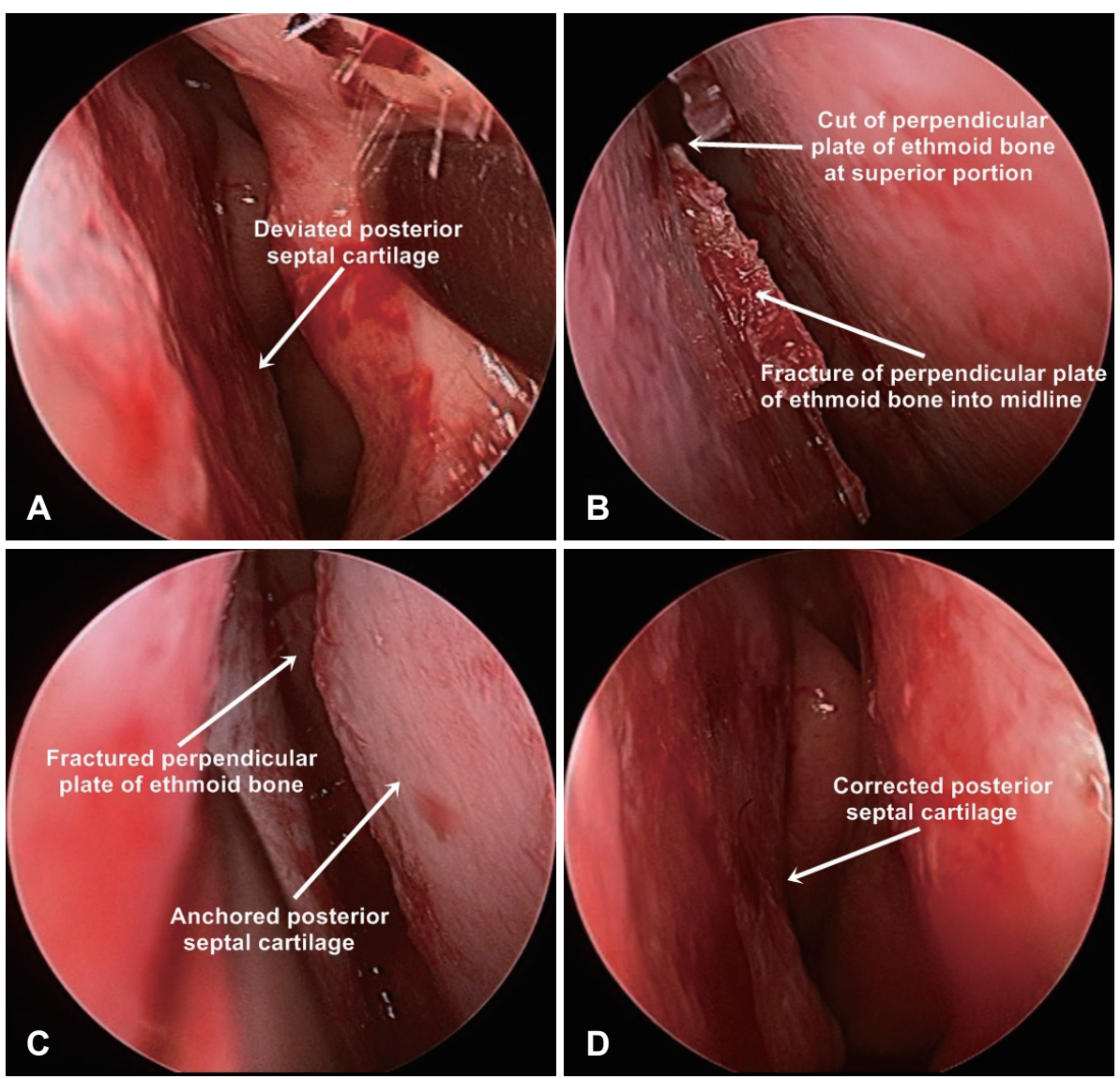

Table 1. Patient characteristics at baseline $(n=44)$

\begin{tabular}{lc}
\hline \multicolumn{1}{c}{ Variables } & Number or mean \pm SD \\
\hline Gender, male/female & $39 / 5$ \\
Age, year & $34.9 \pm 14.4$ \\
Follow-up periods, month & $14.0 \pm 1.7$ \\
History of nasal trauma (\%) & $13(29.5)$ \\
Fracture of nasal septum (\%) & $5(11.4)$ \\
Major portion of septal deviation (\%) & \\
Dorsal portion & $7(15.9)$ \\
Caudal portion & $18(40.9)$ \\
Middle or posterior portion & $13(29.5)$ \\
Crest & $6(13.6)$ \\
Degree of septal deviation (\%) & \\
Severe & $8(18.2)$ \\
Moderate & $32(72.7)$ \\
Mild & $4(9.1)$ \\
\hline
\end{tabular}

Continuous data are presented as number or mean with range. SD: standard deviation

법이 추가적으로 시행되었다.

수술 전 평균 코막힘 VAS 점수는 $7.5 \pm 1.7$ 점이었고, 수술 후 $2.4 \pm 1.4$ 점으로 유의하게 감소되었다 $(p<0.001)$. 음향 비강 통기도 검사에서 비중격 만곡이 있는 비강의 최소 단면적은
수술 전 $0.35 \pm 0.18 \mathrm{~cm}^{2}$ 였고, 수술 후 $0.52 \pm 1.40 \mathrm{~cm}^{2}$ 로 유의 하게 증가하였고 $(p<0.001)$, 부피는 수술 전 $3.6 \pm 1.1 \mathrm{~cm}^{3}$ 에서 수술 후 $5.8 \pm 1.5 \mathrm{~cm}^{3}$ 로 유의하게 증가하였다. 술자가 평가한 비중격 만곡 수술의 결과는 아주 잘 교정됨 8 명, 잘 교정됨 31 명, 양호함 3 명, 교정이 잘 안 됨 2 명이었고, 수술 전보다 악화된 경우는 없었다. 수술 후 비중격 혈종이나 농양, 출혈, 감염, 유착과 같은 합병증이 발생한 환자는 없었고, 1 년의 경 과관찰 기간 동안 만곡이 다시 재발하거나 재수술을 한 경우 는 없었다.

\section{고 찰}

비중격 만곡의 앞쪽은 고정봉합법을 사용하여 봉합 시 당 겨지는 힘으로 교정할 수 있다. 하지만, 뒤쪽의 만곡은 고정 봉합법으로는 교정이 쉽지 않고 경우에 따라서는 시소처럼 앞쪽이 한쪽 방향으로 당겨지면 뒤쪽은 반대편 방향으로 휘 어져서 오히려 비중격 만곡이 악화되는 경우도 발생한다. 비 중격 뒤쪽 만곡에서 골부는 주로 제거하거나 골절시켜서 교 정한다. 뒤쪽의 만곡된 연골을 골절시킬 수는 없으니 주로 절제를 통해 교정하는데, 제거하는 방법을 사용하면 비첨이 
낮아지는 문제가 생길 수 있다. Zoumalan 등ㄱ)의 사체(fresh cadaver) 연구에 의하면, 비중격 연골 중간 부위에 $2 \times 2 \mathrm{~cm}$ 크기의 연골을 제거한 경우 $50 \%$ 에서 비첨이 낮아졌고, 미부 와 배부에 $2 \mathrm{~cm}$ 의 연골을 남겨서 L형 지주(L-strut)를 보존 하여도 모든 사체에서 비첨이 낮아졌음을 보고하였다. 따라 서 외비가 변형되는 합병증을 줄이기 위해서는 L형 지주 외 의 비중격 연골 또한 최대한 보존할 필요가 있다.

또한 절제법으로 교정한 비중격 부위는 양측 비강의 점막 만 남게 되는데, 이러한 부분이 있으면 재수술을 시행할 때 점 막 거상을 매우 어렵게 만들며 쉽게 점막이 찢어져서 비중격 천공이 발생하기 쉽다. 게다가 추후에 비성형술을 시행하게 될 경우 절제법을 시행한 환자에서는 연골과 골의 일부가 제 거되었기 때문에 원하는 만큼의 이식 재료를 얻지 못할 수 있 다. 따라서 저자들은 연골이나 골의 절제 없이 비중격 뒤쪽 을 교정할 수 있는 보존적인 방법인 골고정법을 고안하였다.

고정봉합법과 골고정법을 이용하여 수술한 후 환자의 주 관적인 코막힘은 크게 호전되었고, 객관적인 검사인 음향 비 강통기도 검사에서도 유의한 호전을 나타내었다. 술자가 판단 한 수술 결과도 $95 \%$ 에서 성공적으로 교정되었으며, 만족스 럽지 않게 교정된 2명의 환자는 모두 배부에서 만곡이 남아 있었다. 비중격의 배부는 L형 지주를 보존해야 하기 때문에 교정이 어려워서 이러한 환자들에게 체외 비중격교정술을 권했지만 비용이나 수술시간 등의 이유로 비내 접근법을 원 해서 제한적인 교정이 되었다. 하지만 이러한 환자들에서도 수술 후 코막힘이 모두 호전되어 추가적인 처치는 필요하지 않았다.

골고정법의 제한점은 모든 환자에게 사용할 수 있는 방법 은 아니다. 골절된 골이 비중격 중간 위치에서 유지되기 위해 서는 사골 수직판이 어느 정도의 두께와 강도가 있어야 한다. 골절된 골이 유지되는 힘이 약한 경우에 사용하기 어렵고, 능 (crest)이나 극(spur)을 절제할 수밖에 없어서 절제로 인해 골 절시킬 골이 충분하지 않은 경우에도 사용하기 힘들다. 또한 골절시킨 골에 비중격 연골이 충분히 겹쳐지기 위해서는 만
곡의 정도가 경한 환자에서는 시행하기 어렵다. 골고정법은 골과 연골을 봉합하지 않고 겹치는 방법으로 교정하기 때문 에 고정되는 힘이 약할 수 있어서 시간이 지나면 다시 만곡이 발생할 수도 있다. 하지만 수술 시 비중격 연골을 주위의 장 력으로부터 자유롭게 만든 상태에서 고정하기 때문에 다시 만곡이 발생할 가능성이 높지 않을 것으로 예상하였고, 실제 1 년 이상의 추적관찰 기간 동안 골고정한 부위에서 저명한 만곡의 재발은 관찰되지 않았다.

지금까지 소개된 다양한 비중격 수술 방법들은 주로 미부 를 교정하는 방법들로 비중격 뒷부분을 교정하는 방법은 많 지 않다. 1,4,7-10) 절제 외에는 적절한 방법이 없는 이 부위의 만 곡을 저자들이 고안한 골고정법을 사용해 교정한 결과 좋은 결과를 보였다. 따라서 골고정법은 쉽고 보존적인 방법으로 비중격을 교정할 수 있는 좋은 방법으로 보인다.

\section{REFERENCES}

1) Ahn BH. A practical and clinical application of the septoplasty. Korean J Otorhinolaryngol-Head Neck Surg 2015;58(2):79-87.

2) Most SP, Rudy SF. Septoplasty: basic and advanced techniques. Facial Plast Surg Clin North Am 2017;25(2):161-9.

3) Jin HR, Won TB. Septoplasty: current concept and technique. J Rhinol 2008;15(1):13-29.

4) Kim JH, Kim DY, Jang YJ. Outcomes after endonasal septoplasty using caudal septal batten grafting. Am J Rhinol Allergy 2011;25(4): e166-70.

5) Song SH, Nam WH, Kim JS. Anchoring suture for correction of septal deviation. J Rhinol 2006;13(1):18-21.

6) Guyuron B, Uzzo CD, Scull H. A practical classification of septonasal deviation and an effective guide to septal surgery. Plast Reconstr Surg 1999;104(7):2202-9; discussion 2210-2.

7) Zoumalan RA, Morris LG, Zeitler DM, Shah AR. Effects of various submucous resection techniques of septal cartilage on nasal tip projection. Int Forum Allergy Rhinol 2011;1(1):78-82.

8) Choi BJ, Lee SJ, Park SC, Cho JH, Park YJ, Kim SW. Anchoring suture for the correction of anterior nasal septal deviation. Korean J Otorhinolaryngol-Head Neck Surg 2008;51(8):722-5.

9) Jang YJ, Yeo NK, Wang JH. Cutting and suture technique of the caudal septal cartilage for the management of caudal septal deviation. Arch Otolaryngol Head Neck Surg 2009;135(12):1256-60.

10) Kim YD. Septoplasty and turbinoplasty; current concept and technique. J Rhinol 2012;19(1):19-28. 